\title{
Editorial: Improving visual deficits with perceptual learning
}

\author{
Gianluca Campana $^{1,2 *}$ and Marcello Maniglia ${ }^{3,4}$ \\ ${ }^{1}$ Department of General Psychology, University of Padova, Padova, Italy, ${ }^{2}$ Human Inspired Technologies Research \\ Centre - HIT, University of Padova, Padova, Italy, ${ }^{3}$ Centre de Recherche Cerveau et Cognition, Université de Toulouse-UPS, \\ Toulouse, France, ${ }^{4}$ Centre National de la Recherche Scientifique, Toulouse, France
}

Keywords: myopia, presbyopia, amblyopia, crowding, nystagmus, tRNS, macular degeneration, blindness

\section{OPEN ACCESS}

Edited and reviewed by: Philippe G. Schyns,

University of Glasgow, UK

*Correspondence:

Gianluca Campana,

gianluca.campana@unipd.it

Specialty section:

This article was submitted to

Perception Science,

a section of the journal

Frontiers in Psychology

Received: 18 March 2015 Accepted: 06 April 2015

Published: 21 April 2015

Citation:

Campana G and Maniglia M (2015) Editorial: Improving visual deficits with perceptual learning.

Front. Psychol. 6:491. doi: 10.3389/fpsyg.2015.00491
The capability of improving performance on visual tasks with practice has been a matter of intense investigation during the last 40 years (Fiorentini and Berardi, 1980; Sagi, 2011). This phenomenon, called perceptual learning, has been proven to occur with virtually any visual skill or stimulus characteristic (Fahle and Poggio, 2002), and to be long-lasting, thus involving neural plasticity at the level of perceptual or even sensory areas (Sagi and Tanne, 1994). Despite this, only recently has perceptual learning started to be considered a useful tool for improving visual functions in clinical populations. This delayed exploitation has possibly been caused by the common finding that learning was highly specific for the trained stimulus attributes (Fiorentini and Berardi, 1980; Ball and Sekuler, 1981; Ahissar and Hochstein, 1996; Schoups et al., 2001; Campana and Casco, 2003; Fahle, 2005), or even for the trained eye or retinal location (Karni and Sagi, 1991), thus resulting impractical for therapeutic purposes. More recently it has become clear that, under specific training conditions, perceptual learning could generalize to other stimuli, tasks and circumstances (McGovern et al., 2012), yielding potential benefits for various types of visual impairments. So far, perceptual learning has been shown to be effective in improving, among other dysfunctions, visual abilities in amblyopia (Levi and Li, 2009; Polat, 2009; Hussain et al., 2012), mild refractive defects (myopia: Tan and Fong, 2008; Camilleri et al., 2014a; presbyopia: Polat et al., 2012), central or peripheral vision loss and cortical blindness (Kasten et al., 1998; Sabel et al., 2005; Huxlin et al., 2009; Chung, 2011; Das et al., 2014), dyslexia (Gori and Facoetti, 2015), and has even been shown to improve the efficacy of other sensory modalities so that they can somehow replace vision (so called sensory substitution) in blind people (Bach-y-Rita and Kercel, 2003; Ortiz et al., 2011).

The goal of this Research Topic is to demonstrate the development of innovative methods, based on perceptual learning, for treating-or at least overcoming some of the deleterious effects of-various visual dysfunctions, from mild deficits such as myopia to complete blindness. New frontier methods should aim at finding the most effective procedures both in terms of perceptual learning and transfer to useful visual functions. This is made possible by combining different techniques aimed at boosting learning or its generalization, such as training with different stimulus features (Xiao et al., 2008; Harris et al., 2012), exploiting multisensory facilitation (Shams and Seitz, 2008) and reinforcement procedures (Seitz and Watanabe, 2009), or combining perceptual learning with non-invasive brain stimulation procedures (Fertonani et al., 2011). Also, in order to achieve the best possible compliance with the patients, shorter and/or more enjoyable trainings (possibly self-administered at home) should be preferred.

For example, while training on either off-the shelf video games (Li et al., 2011; Franceschini et al., 2013), or specifically designed video games involving detection of low contrast stimuli (Deveau et al., 2014a,b) has been shown to improve a range of visual functions (visual acuity, contrast sensitivity, reading skills and even sport performances) both in normally sighted people and people with developmental dyslexia or amblyopia, in the present Research Topic we see that the latter type of video games can also improve visual acuity in participants with refractive defects such presbyopia 
(Deveau and Seitz, 2014) or reduce crowding (the deleterious effect of nearby elements on target's perception; Levi, 2008) in participants with cortical deficits such as amblyopia (Hussain et al., 2014). While negligible in normal foveal vision, crowding is an important issue also in children with visual impairment accompanied by nystagmus. Reduction of crowding in these children (besides an improvement of near visual acuity, see Huurneman et al., 2013) can be obtained with training on crowded letters, thus producing faster reaction times and an increase of fixation durations (Huurneman and Boonstra, 2014).

Visual functions in participants with mild refractive defects or amblyopia have also been shown to considerably improve with contrast detection trainings (with or without lateral masking) (Tan and Fong, 2008; Levi and Li, 2009; Polat, 2009; Polat et al., 2012; Camilleri et al., 2014a). Here we see how, both in mild myopia and amblyopia, combining a contrast detection training with non-invasive brain stimulation (specifically, transcranial random noise stimulation-tRNS) seems to yield to faster/more effective perceptual learning and transfer to visual acuity and contrast sensitivity (Camilleri et al., 2014b; Campana et al., 2014).

Perceptual learning can also be successfully applied to patients with loss of central vision. Indeed, past research has shown, in sighted participants, how perceptual learning on a contrast detection task with lateral masking was able to reduce crowding at eccentric retinal locations (Maniglia et al., 2011). Here we see how, in patients with macular degeneration, eccentric perceptual learning with a rapid serial visual presentation (RSVP) produces an improvement in reading speed mainly with supra-threshold

\section{References}

Ahissar, M., and Hochstein, S. (1996). Learning pop-out detection: specificities to stimulus characteristics. Vision Res. 36, 3487-3500.

Bach-y-Rita, P., and Kercel, S. W. (2003). Sensory substitution and the humanmachine interface. Trends Cogn. Sci. 7, 541-546. doi: 10.1016/j.tics.2003.10.013

Ball, K., and Sekuler, R. (1981). Adaptive processing of visual motion. J. Exp. Psychol. Hum. Percept. Perform. 7, 780-794.

Camilleri, R., Pavan, A., Ghin, F., Battaglini, L., and Campana, G. (2014b). Improvement of uncorrected visual acuity and contrast sensitivity with perceptual learning and transcranial random noise stimulation in individuals with mild myopia. Front. Psychol. 5:1234. doi: 10.3389/fpsyg.2014.01234

Camilleri, R., Pavan, A., Ghin, F., and Campana, G. (2014a). Improving myopia via perceptual learning: is training with lateral masking the only (or the most) efficacious technique? Atten. Percept. Psychophys. 76, 2485-2494. doi: 10.3758/s13414-014-0738-8

Campana, G., Camilleri, R., Pavan, A., Veronese, A., and Lo Giudice, G. (2014). Improving visual functions in adult amblyopia with combined perceptual training and transcranial random noise stimulation (tRNS): a pilot study. Front. Psychol. 5:1402. doi: 10.3389/fpsyg.2014.01402

Campana, G., and Casco, C. (2003). Learning in combined-feature search: specificity to orientation. Percept. Psychophys. 65, 1197-1207. doi: 10.3758/BF03194845

Chung, S. T. (2011). Improving reading speed for people with central vision loss through perceptual learning. Invest. Ophthalmol. Vis. Sci. 52, 1164-1170. doi: 10.1167/iovs.10-6034

Coates, D. R., and Chung, S. T. (2014). Changes across the psychometric function following perceptual learning of an RSVP reading task. Front. Psychol. 5:1434. doi: 10.3389/fpsyg.2014.01434 word durations (above $200 \mathrm{~ms}$ ) (Coates and Chung, 2014), while a texture discrimination training enhances temporal processing of eccentric stimuli (reflected in shorter stimulus onset asynchrony needed for discrimination), especially when fixation was stable (Plank et al., 2014).

In fact improved temporal processing in areas of residual vision (besides an extension of such areas) in patients with vision loss (hemianopia or quadrantanopia) can be also obtained with the so-called vision restoration therapy, an individualized program providing stimulation at the border of the dysfunctional visual field (Poggel et al., 2014).

Finally, perceptual learning could be useful even for blind people. Blindness often produces an impaired spatial representation in other sensory domains (e.g., Gori et al., 2014a). Here it is shown that blindfolded sighted participants can learn an auditory spatial bisection task, but improvements only occur when a tactile feedback is delivered, indicating that the tactile system can be used to recalibrate the spatial representation in the auditory domain (Gori et al., 2014b). This finding suggests that, also in blind people, auditory spatial representation can be improved via tactile feedback.

To sum up the findings of the present Research Topic, the studies collected here provide the frontline of behavioral and brain stimulation-coupled treatments of a heterogeneous ensemble of visual dysfunctions. Future studies are needed to define the best combination of approaches in order to improve vision with the shortest and most efficacious training, increasing patients' compliance and tailoring the training specifically for each patients' needs.

Das, A., Tadin, D., and Huxlin, K. R. (2014). Beyond blindsight: properties of visual relearning in cortically blind fields. J. Neurosci. 34, 11652-11664. doi: 10.1523/JNEUROSCI.1076-14.2014

Deveau, J., Lovcik, G., and Seitz, A. R. (2014a). Broad-based visual benefits from training with an integrated perceptual-learning video game. Vision Res. 99, 134-140. doi: 10.1016/j.visres.2013

Deveau, J., Ozer, D. J., and Seitz, A. R. (2014b). Improved vision and on-field performance in baseball through perceptual learning. Curr. Biol. 24, R146-R147. doi: 10.1016/j.cub.2014.01.004

Deveau, J., and Seitz, A. R. (2014). Applying perceptual learning to achieve practical changes in vision. Front. Psychol. 5:1166. doi: 10.3389/fpsyg.2014. 01166

Fahle, M. (2005). Perceptual learning: Specificity versus generalization. Curr. Op. Neurobiol. 15, 154-160. doi: 10.1016/j.conb.2005.03.010

Fahle, M., and Poggio, T. (2002). Perceptual Learning. Cambridge, MA: MIT Press. Fertonani, A., Pirulli, C., and Miniussi, C. (2011). Random noise stimulation improves neuroplasticity in perceptual learning. J. Neurosci. 31, 15416-15423. doi: 10.1523/JNEUROSCI.2002-11.2011

Fiorentini, A., and Berardi, N. (1980). Perceptual learning specific for orientation and spatial frequency. Nature 287, 43-44.

Franceschini, S., Gori, S., Ruffino, M., Viola, S., Molteni, M., and Facoetti, A. (2013). Action video games make dyslexic children read better. Curr. Biol. 23, 462-466. doi: 10.1016/j.cub.2013.01.044

Gori, M., Sandini, G., Martinoli, C., and Burr, D. C. (2014a). Impairment of auditory spatial localization in congenitally blind human subjects. Brain 137(Pt 1), 288-293. doi: 10.1093/brain/awt311

Gori, M., Vercillo, T., Sandini, G., and Burr, D. (2014b). Tactile feedback improves auditory spatial localization. Front. Psychol. 5:1121. doi: 10.3389/fpsyg.2014.01121 
Gori, S., and Facoetti, A. (2015). How the visual aspects can be crucial in reading acquisition? The intriguing case of crowding and developmental dyslexia. J. Vis. 15, 1-20. doi: 10.1167/15.1.8

Harris, H., Gliksberg, M., and Sagi, D. (2012). Generalized perceptual learning in the absence of sensory adaptation. Curr. Biol. 22, 1813-1817. doi: 10.1016/j.cub.2012.07.059

Hussain, Z., Astle, A. T., Webb, B. S., and McGraw, P. V. (2014). The challenges of developing a contrast-based video game for treatment of amblyopia. Front. Psychol. 5:1210. doi: 10.3389/fpsyg.2014.01210

Hussain, Z., Webb, B. S., Astle, A. T., and McGraw, P. V. (2012). Perceptual learning reduces crowding in amblyopia and in the normal periphery. J. Neurosci. 32, 474-480. doi: 10.1523/JNEUROSCI.3845-11.2012

Huurneman, B., and Boonstra, F. N. (2014). Training shortens search times in children with visual impairment accompanied by nystagmus. Front. Psychol. 5:988. doi: 10.3389/fpsyg.2014.00988

Huurneman, B., Boonstra, F. N., Cox, R. F., Van Rens, G., and Cillessen, A. H. (2013). Perceptual learning in children with visual impairment improves near visual acuity. Invest. Ophthalmol. Vis. Sci. 54, 6208-6216. doi: 10.1167/iovs.1312220

Huxlin, K. R., Martin, T., Kelly, K., Riley, M., Friedman, D. I., Burgin, W. S., et al. (2009). Perceptual relearning of complex visual motion after V1 damage in humans. J. Neurosci. 29, 3981-3991. doi: 10.1523/JNEUROSCI.4882-08.2009

Karni, A., and Sagi, D. (1991). Where practice makes perfect in texture discrimination: evidence for primary visual cortex plasticity. Proc. Natl. Acad. Sci. U.S.A. 88, 4966-4970.

Kasten, E., Wüst, S., Behrens-Baumann, W., and Sabel, B. A. (1998). Computerbased training for the treatment of partial blindness. Nat. Med. 4, 1083-1087.

Levi, D. M. (2008). Crowding-An essential bottleneck for object recognition: a mini-review. Vision Res. 48, 635-654. doi: 10.1016/j.visres.2007.12.009

Levi, D. M., and Li, R. W. (2009). Perceptual learning as a potential treatment for amblyopia: a mini-review. Vision Res. 49, 2535-2549. doi: 10.1016/j.visres.2009.02.010

Li, R. W., Ngo, C., Nguyen, J., and Levi, D. M. (2011). Video-game play induces plasticity in the visual system of adults with amblyopia. PLoS Biol. 9:e1001135. doi: 10.1371/journal.pbio.1001135

Maniglia, M., Pavan, A., Cuturi, L. F., Campana, G., Sato, G., and Casco, C. (2011). Reducing crowding by weakening inhibitory lateral interactions in the periphery with perceptual learning. PLoS ONE 6:e25568. doi: 10.1371/journal.pone. 0025568

McGovern, D. P., Webb, B. S., and Peirce, J. W. (2012). Transfer of perceptual learning between different visual tasks. J. Vis. 12:4. doi: 10.1167/12.11.4

Ortiz, T., Poch, J., Santos, J., Requena, C., Martinez, A., Ortiz-Teran, L., et al. (2011). Recruitment of occipital cortex during sensory substitution training linked to subjective experience of seeing in people with blindness. PLOS ONE 6:e23264. doi: 10.1371/journal.pone.0023264
Plank, T., Rosengarth, K., Schmalhofer, C., Goldhacker, M., Brandl-Rühle, S., and Greenlee, M. W. (2014). Perceptual learning in patients with macular degeneration. Front. Psychol. 5:1189. doi: 10.3389/fpsyg.2014. 01189

Poggel, D. A., Treutwein, B., Sabel, B. A., and Strasburger, H. (2014). A matter of time: improvement of visual temporal processing during traininginduced restoration of light detection performance. Front. Psychol. 6:22. doi: 10.3389/fpsyg. 2015.00022

Polat, U. (2009). Making perceptual learning practical to improve visual functions Vis. Res. 49, 2566-2573. doi: 10.1016/j.visres.2009.06.005

Polat, U., Schor, C., Tong, J. L., Zomet, A., Lev, M., Yehezkel, O., et al. (2012). Training the brain to overcome the effect of aging on the human eye. Sci. Rep. 2:278. doi: $10.1038 /$ srep00278

Sabel, B. A., Kenkel, S., and Kasten, E. (2005). Vision restoration therapy. Br. J. Ophthalmol. 89, 522-524. doi: 10.1136/bjo.2005.068163

Sagi, D. (2011). Perceptual learning in Vision Research. Vision Res. 51, 1552-1566. doi: 10.1016/j.visres.2010.10.019

Sagi, D., and Tanne, D. (1994). Perceptual learning: learning to see. Curr. Opin. Neurobiol. 4, 195-199.

Schoups, A., Vogels, R., Qian, N., and Orban, G. (2001). Practicing orientation identification improves orientation coding in V1 neurons. Nature 412, 549-553. doi: $10.1038 / 35087601$

Seitz, A. R., and Watanabe, T. (2009). The phenomenon of task-irrelevant perceptual learning. Vision Res. 49, 2604-2610. doi: 10.1016/j.visres. 2009.08.003

Shams, L., and Seitz, A. R. (2008). Benefits of multisensory learning. Trends Cogn. Sci. 12, 411-417. doi: 10.1016/j.tics.2008.07.006

Tan, D. T., and Fong, A. (2008). Efficacy of neural vision therapy to enhance contrast sensitivity function and visual acuity in low myopia. J. Cataract Refract. Surg. 34, 570-577. doi: 10.1016/j.jcrs.2007.11.052

Xiao, L. Q., Zhang, J. Y., Wang, R., Klein, S. A., Levi, D. M., and Yu, C. (2008). Complete transfer of perceptual learning across retinal locations enabled by double training. Curr. Biol. 18, 1922-1926. doi: 10.1016/j.cub.2008. 10.030

Conflict of Interest Statement: The authors declare that the research was conducted in the absence of any commercial or financial relationships that could be construed as a potential conflict of interest.

Copyright () 2015 Campana and Maniglia. This is an open-access article distributed under the terms of the Creative Commons Attribution License (CC BY). The use, distribution or reproduction in other forums is permitted, provided the original author(s) or licensor are credited and that the original publication in this journal is cited, in accordance with accepted academic practice. No use, distribution or reproduction is permitted which does not comply with these terms. 